\title{
The impact of perioperative anaemia on length of hospital stay in patients undergoing hemicolectomy surgery
}

\author{
A retrospective study
}

Wellstead $\mathbf{G}^{1}$, Chequer $\mathbf{S}^{1}$

1. Lister Hospital East and North Hertfordshire NHS Trust

\section{Introduction}

Co-morbidities such as anaemia are associated with higher complication and mortality rates following surgery ${ }^{1,2}$. Preoperative anaemia is also associated with extended post-operative hospital admissions. However it is not clear if this is because anaemia represents worse underlying pathology necessitating surgery or represents an additional surgical risk itself ${ }^{3}$.

Pre-operative optimisation of a patients' haemoglobin can improve patient outcomes and decrease length of stay in hospital, if detected and treated early ${ }^{4}$

The aim of this study was to investigate the association between perioperative anaemia and blood transfusions with postoperative length of stay in hospital for patients undergoing emergency and elective hemicolectomies.

\section{Methods}

We performed a retrospective study looking at pre- and postoperative haemoglobin $(\mathrm{Hb})$ levels for all patients undergoing elective or emergency hemicolectomies between 01/07/15 and 30/06/16 at The Lister Hospital, Stevenage.

Our primary outcome was length of postoperative stay in hospital. We also looked at the impact of intraoperative and postoperative blood transfusion.

\section{Results}

Of the 62 elective and 23 emergency hemicolectomies $(n=85)$ that were analysed, $21 \%$ underwent transfusion of blood products postoperatively.

$59 \%$ of patients were anaemic pre-procedure and the mean change in haemoglobin levels was $\Delta-11.59 \mathrm{~g} / \mathrm{dL}$ resulting in a total of $85 \%$ of patients being anaemic postoperatively.

The majority of postoperative blood transfusions were in elective cases $(71 \%)$. Furthermore, a higher proportion of elective patients were preoperatively anaemic $(61 \%)$ than emergency patients $(50 \%)$

\begin{tabular}{|l|c|c|}
\hline & $\begin{array}{c}\text { Elective } \\
(\mathbf{n = 6 2 )}\end{array}$ & $\begin{array}{c}\text { Emergency } \\
(\mathbf{n = 2 3 )}\end{array}$ \\
\hline Preoperatively anaemic (\%) & $61.3 \%$ & $52.2 \%$ \\
\hline Postoperatively anaemic (\%) & $88.7 \%$ & $69.6 \%$ \\
\hline Mean change in Hb (g/dL) & -13.70 & -5.91 \\
\hline Transfused (\%) & $27.4 \%$ & $30.4 \%$ \\
\hline
\end{tabular}

Table 1: Anaemia and transfusion data for elective vs. emergency hemicolectomy patients

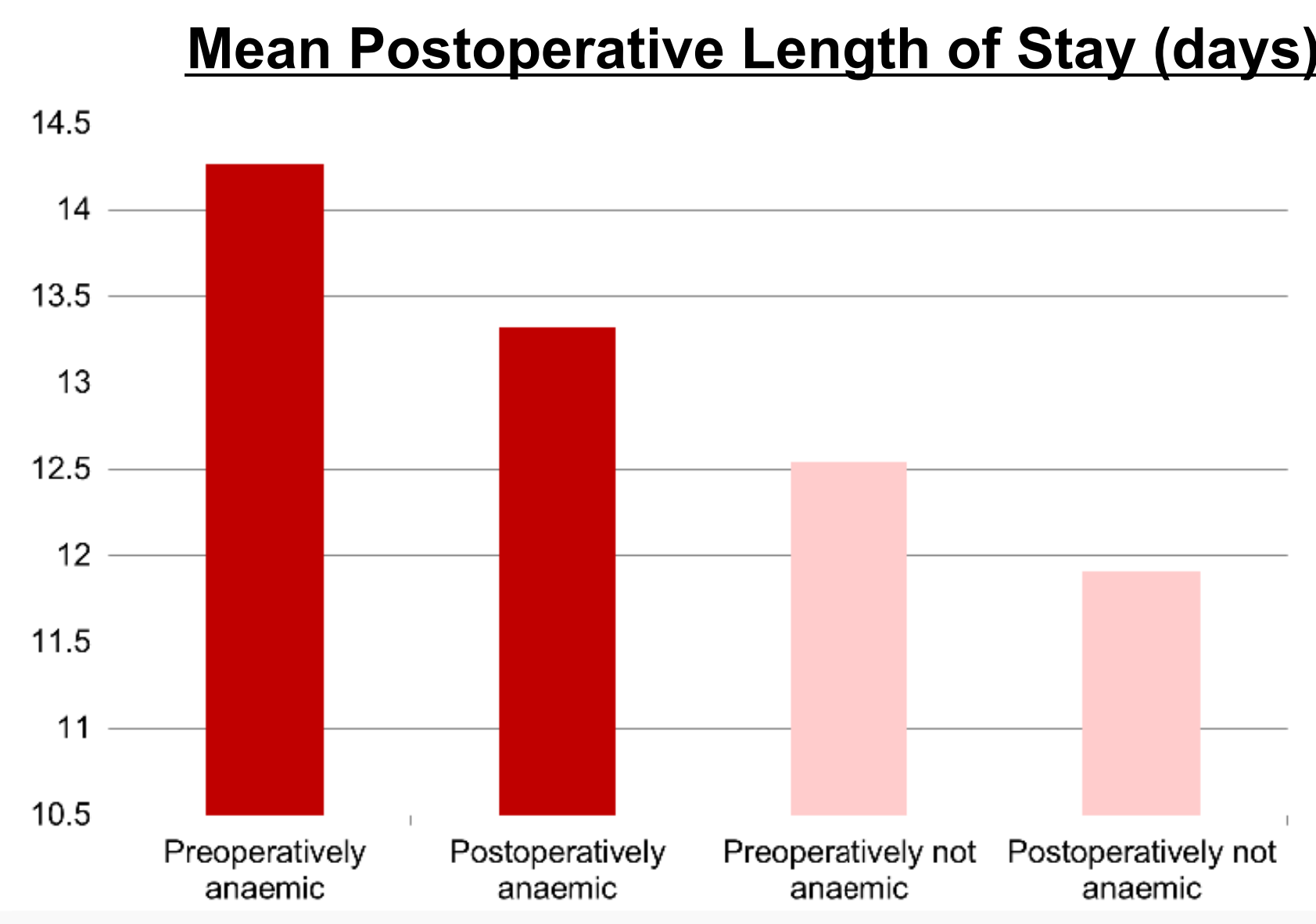

Figure 1: Length of stay vs anaemia

The mean length of stay post-procedure was 13.40 days (SD 14.11) and length of stay was longest for preoperatively anaemic patients (figure 1).

Postoperative transfusions were associated with a higher mean length of stay (25.48 days) compared with patients who were not transfused (9.44 days)

\section{Conclusion}

Overall, anaemia is associated with a longer length of stay post procedure with preoperative anaemia resulting in the longest length of stay.

A higher proportion of elective patients were preoperatively anaemeic and the majority of postoperative transfusions were performed after elective cases.

Preoperative assessment clinics are routine for elective surgery at The Lister. Anaemia can be diagnosed preoperatively and patients should have their haemoglobin optimized through ambulatory care services ${ }^{4}$. Single intravenous iron infusions are proven to be a feasible and cost effective way to address this ${ }^{5}$

\section{References}

1 - Dunne, J.R., Malone, D., Tracy, J.K., Gannon, C. and Napolitano, L.M., 2002. Perioperative anemia: an independent risk factor for infection, mortality, and resource utilization in surgery. Journal of Surgical Research, 102(2), pp.237-244.

2 - Musallam, K.M., Tamim, H.M., Richards, T., Spahn, D.R., Rosendaal, F.R., Habbal, A., Khreiss, M., Dahdaleh, F.S., Khavandi, K., Sfeir, P.M. and Soweid, A., 2011. Preoperative anaemia and postoperative outcomes in non-cardiac surgery: a retrospective cohort study. The Lancet, 378(9800), pp.1396-1407.

3 - Lunn, J.N. and Elwood, P.C., 1970. Anaemia and surgery. Br Med J, 3(5714), pp.71-73.

4 - Muñoz, M., Gómez-Ramírez, S., Kozek-Langeneker, S., Shander, A., Richards, T., Pavía, J., Kehlet, H., Acheson, A.G., Evans, C., Raobaikady, R. and Javidroozi, M., 2015. 'Fit to fly' overcoming barriers to preoperative haemoglobin optimization in surgical patients. British journal of anaesthesia, 115(1), pp.15-24.

5 - Keeler, B., Simpson, J.A., Ng, S., Tselepis, C., Iqbal, T., Brookes, M.J. and Acheson, A.G., 2014 The feasibility and clinical efficacy of intravenous iron administration for preoperative anaemia in patients with colorectal cancer. Colorectal Disease, 16(10), pp.794-800. 